\title{
A Smart Recipe of Chemistry and Management
}

\author{
Stefan Seeger
}

\begin{abstract}
The Bachelor and Master Program in Chemistry and Business Studies has been offered by the Chemical Institutes of the University of Zurich since 2004 to meet the growing demand for graduates with solid scientific and technical background but also management skills. The program has attracted a large number of students whilst not affecting the numbers in the chemistry program showing that young people are attracted who would not otherwise have chosen a science degree. Future planned development of the program includes more input from the chemical industry and creation of international contacts.
\end{abstract}

Keywords: Chemistry and Business Studies · UZH

\section{"A Smart Recipe of Chemistry and Management"...}

says a manager from BASF chemical company in Ludwigshafen/Germany. He is talking about a new way to study chemistry: It is called 'Wirtschaftschemie' or 'Chemistry and Business Administration' and was introduced in Switzerland at the University of Zurich in 2004. A growing number of job profiles in the chemical, pharmaceutical and related industries require solid scientific and technical background but also management skills. Product management, key account management, controlling and purchasing are a few examples where chemical

${ }^{\star}$ Correspondence: Prof. Dr. S. Seeger

Physikalisch-Chemisches Institut

Universität Zürich

Winterthurerstrasse 190

$\mathrm{CH}-8057$ Zürich

E-mail: sseeger@pci.uzh.ch background alone is not sufficient to match the requirements.

Looking at the traditional universities' Bachelor and Master Programs in chemistry we find excellent education in inorganic, organic, physical chemistry and biochemistry. Graduates are qualified for laboratory and scientific jobs and in most cases they demonstrate their competency when they write a PhD thesis and scientific publications. During their time in a university research group they work in a small group often with a lot of freedom to explore e.g. new molecules and their properties. This is in most cases in contrast to the reality in industry. Here, the frame looks quite different: cost efficiency, tough time schedules and very precise customer requirements suddenly dominate scientific excellence. Economical and management skills are even more required for chemists starting their career in small and middle-sized enterprises or even young entrepreneurs, where also project financing, controlling, research management and many more are important issues from the first day.

Although the traditional chemistry education is strongly focused on front-end science, which is of course an important sustainer of our economic well-being, a growing number of young people are excited about chemistry and science in general, but they aim at management and not a scientific career. Unfortunately, these highly motivated people often are lost for chemistry, because they often decide against a scienceonly education and prefer e.g. a business and management program.

In conclusion, there has been a missing bridge between job profiles requiring science and management skills and young people wishing a chemistry education including business and management. Chemists are supposed to study management and business as an on-the-job training or they have to interrupt their career for a Master of Business Administration. This is time consuming and cost intensive for both the employee and the company.

Therefore, in 2004 the University of Zurich established a novel Bachelor and Master Program called 'Chemistry and Business Studies'. These programs combine front-end education in chemistry with modern management know how. Students are taught in all central chemistry and chemistry-related fields, like inorganic, organic, physical chemistry, physics and mathematics. All these courses have the same high level as the courses for chemistry students or in other words, students are together with the chemistry students in the same courses. In addition, the main courses of Management provided by the University of Zurich are also part of the program. The latter are visited together with the students of Management and Business affairs, so in both fields, highest level of excellence is guaranteed.

Susanne Neitzel, one of the first graduates in 'Wirtschaftschemie' in Germany, now working as a key account manager, says that her background in business-related fields helps to communicate with customers and understand their needs. Discussions with customers, product managers, production department, marketing and sales people therefore are much more straightforward, because she understands all the needs and limitations, regardless of whether they 


\begin{tabular}{|c|c|c|c|c|c|}
\hline \multicolumn{6}{|c|}{ Core Courses 1st Year } \\
\hline \multicolumn{4}{|l|}{ Module } & Credit Points & Type \\
\hline \multicolumn{6}{|c|}{ Compulsory modules } \\
\hline \multicolumn{4}{|c|}{ CHE 101 Basic chemistry } & 12 & $L+T$ \\
\hline \multicolumn{4}{|c|}{ CHE 111 Basic chemistry lab course, part 1} & 8 & $\mathrm{P}$ \\
\hline \multicolumn{4}{|c|}{ CHE 112 Basic chemistry lab course, part 2} & 8 & $\mathrm{P}$ \\
\hline \multicolumn{4}{|c|}{ MAT 184 Mathematics for chemists } & 8 & $L+T$ \\
\hline \multicolumn{4}{|c|}{ PHY 117 Physics for biologists and chemists I } & 6 & $L+T+P$ \\
\hline \multicolumn{4}{|c|}{ PHY 127 Physics for biologists and chemists II } & 6 & $L+T+P$ \\
\hline \multicolumn{4}{|l|}{ BWL I } & 3 & $L+T$ \\
\hline \multicolumn{4}{|l|}{ BWL II } & 6 & $L+T$ \\
\hline \multicolumn{4}{|c|}{ Financial Accounting } & 6 & $L+T$ \\
\hline \multicolumn{6}{|c|}{ Timetable Fall Semester } \\
\hline \multirow{8}{*}{$\begin{array}{c}8-9 \\
9-10 \\
10-11 \\
11-12 \\
12-13 \\
13-14 \\
14-15 \\
15-16 \\
16-17 \\
17-18\end{array}$} & Monday & \multirow{2}{*}{$\begin{array}{l}\text { Tuesday } \\
\text { Financial } \\
\text { Accounting }\end{array}$} & \multirow[t]{2}{*}{ Wednesday } & \multirow{2}{*}{ BWLI I } & Friday \\
\hline & & & & & PHY 117 \\
\hline & CHE 101 & MAT 184 & CHE 101 & MAT 184 & CHE 101 \\
\hline & & & & PHY 117 & \\
\hline & & & & & \\
\hline & & Financial & CHE 111 & & PHY 117 \\
\hline & & Accounting & & CHE 111 & \\
\hline & & & & & \\
\hline \multicolumn{6}{|c|}{ Timetable Spring Semester } \\
\hline \multirow{9}{*}{$\begin{array}{c}8-9 \\
9-10 \\
10-11 \\
11-12 \\
12-13 \\
13-14 \\
14-15 \\
15-16 \\
16-17 \\
17-18\end{array}$} & Monday & Tuesday & Wednesday & Thursday & Friday \\
\hline & CHE 101 & CHE 101 & CHE 101 & BWL II & PHY 127 \\
\hline & CHE 101 & MAT 184 & MAT 184 & & \\
\hline & & & & PHY 127 & \\
\hline & & \multirow{5}{*}{ CHE 112} & \multirow{3}{*}{ BWL ॥ } & & \multirow{5}{*}{ PHY 127} \\
\hline & & & & & \\
\hline & & & & CHE 112 & \\
\hline & & & & & \\
\hline & & & & & \\
\hline
\end{tabular}

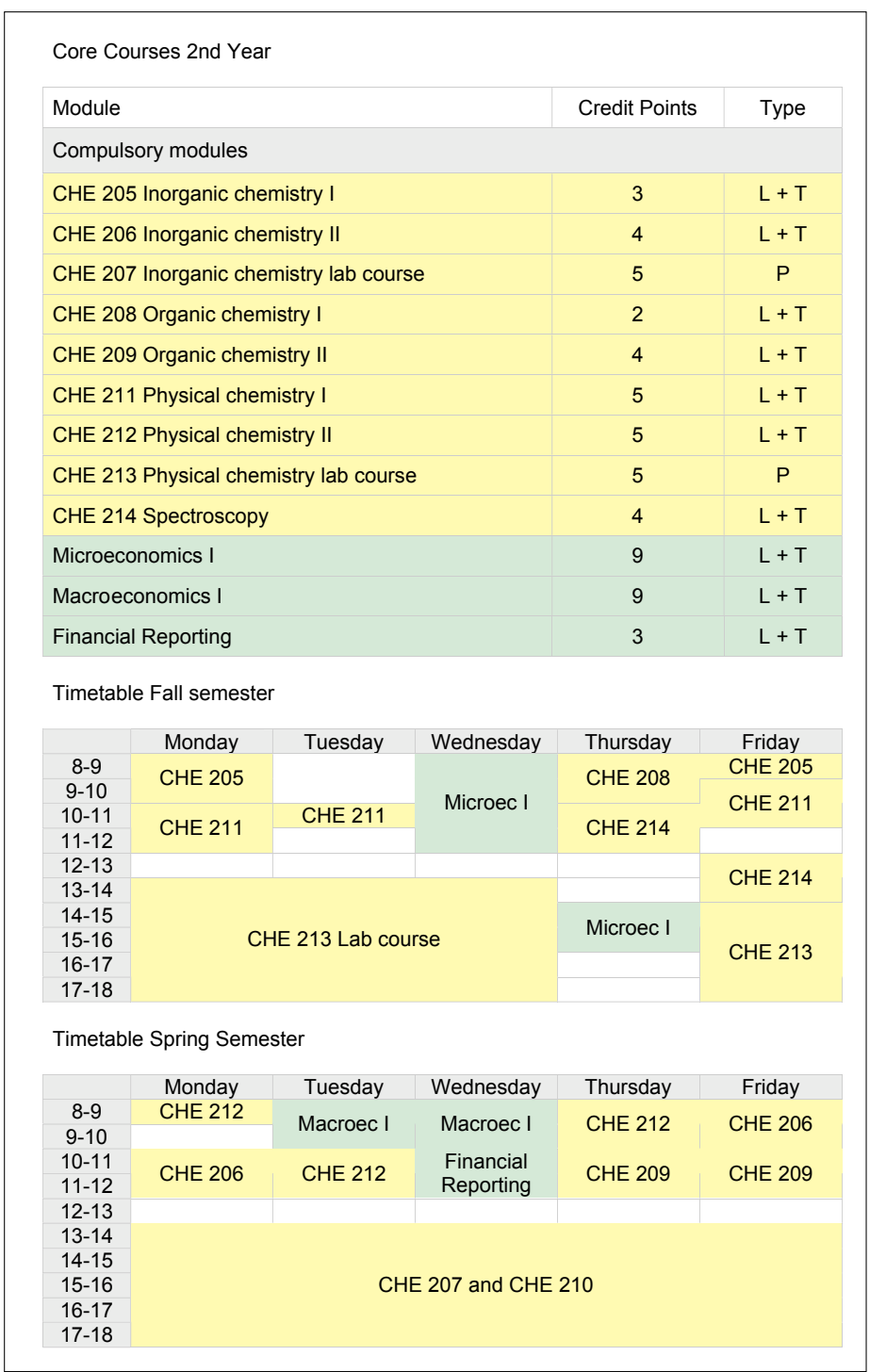

Fig. 1.

are caused by technical or economical facts. Of course, for working at such an interface between product development, application, and production an excellent chemical background is absolutely necessary. "With my background I feel very comfortable in this exciting role", Neitzel says.

The Swiss chemical industry has realized the advantages of such a program and a handful of Chemistry and Business Administration students and graduates have already been hired as practical students, for Master theses and as full professionals (imported from Germany, because the first $\mathrm{Zu}$ rich students started in 2004 and will earn this year their Master degrees).

\section{The Structure of the Zurich Program}

The University of Zurich offers a Bachelor and Master Program in Chemistry and Business Administration. The programs are structured in an integrated way, i.e. the students learn both - science and management
- in parallel from the first day until they hold their degree in their hands.

For example in the first semester, students start with general chemistry, mathematics and physics together with their chemistry colleagues. In addition they read Business Administration 1 (this includes basic management and marketing) and financial accounting. The students do not attend the biology courses, which are obligatory for the chemistry students. Hence, the students have time for the management courses but they are educated at the same high level as the chemistry students. In Fig. 1 the structure of the program is shown indicating a high level and intensive education. One frequently asked question regards the ratio of chemistry and management during the programs. Roughly, our students spend $60-70 \%$ of the time with chemistry-related topics, whereas $30-40 \%$ are management topics.

During the first two years, students attend a fixed program in all classic fields of chemistry, physics, mathematics and business. In the third year they have the op- portunity to select from a series of courses beside the mandatory courses. They are allowed to choose a main chemistry field out of inorganic, organic, physical chemistry. With this strategy we keep the excellence level, i.e. the level of a 'regular' chemist student. Also the width is kept, just shifted: e.g. fewer inorganic complexes, more marketing, or less spectroscopy, more innovation management.

The Master's program contains modules which are specifically designed for the Business Chemistry students: A practical course which has to be completed outside the university, i.e. preferably in chemical or related industry. Further, the Master's program contains two modules of 'Wirtschaftschemie'. These modules teach content which is specific for the responsibilities graduates have to take in their job later. Intellectual property, innovation management, business plan writing are some of the subjects which are taught in these courses. Finally, students have to write a Master's thesis in collaboration with the chemical or related industry. The Master's thesis should be finished 


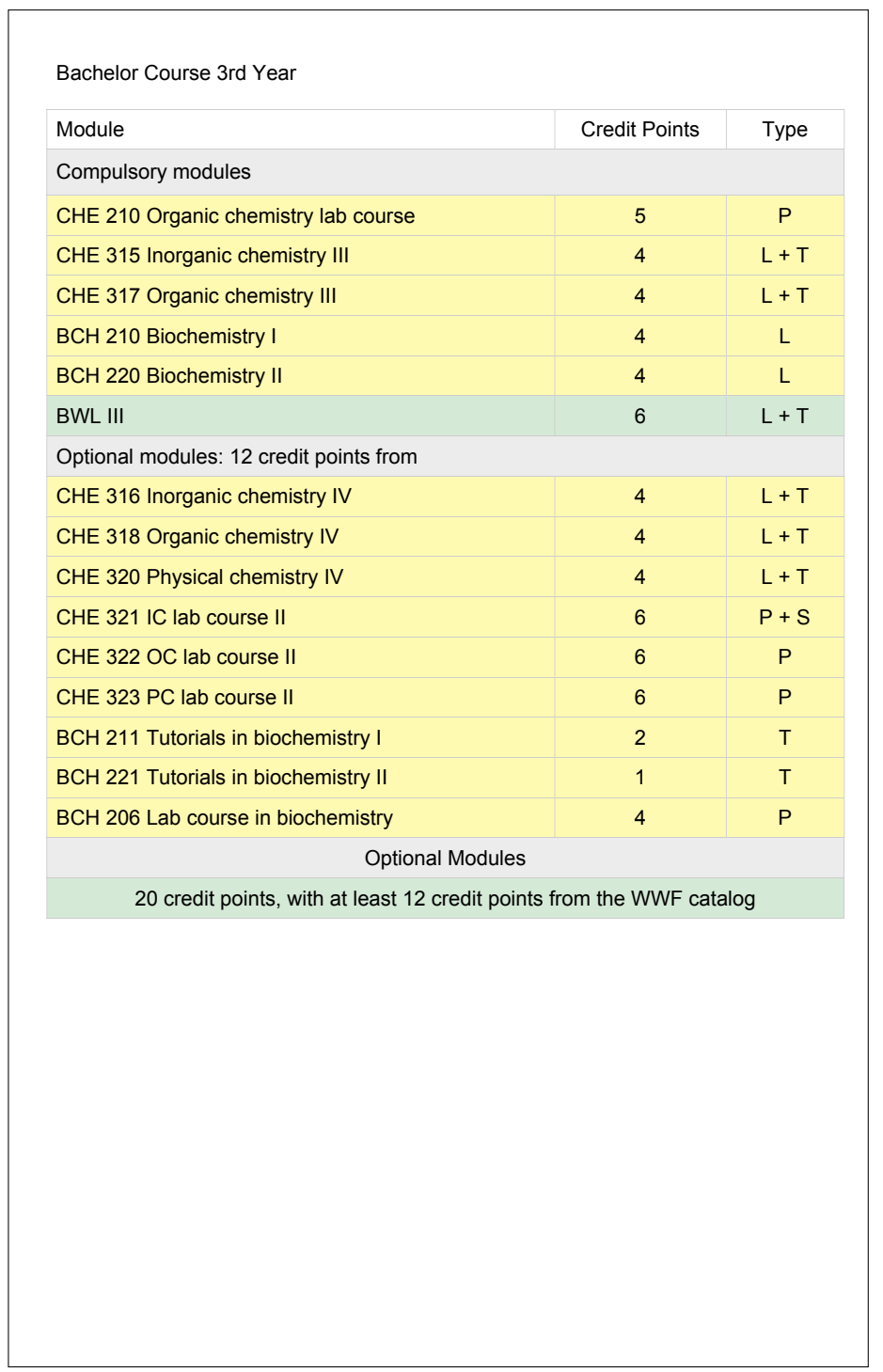

Master's Course 4th/5th Year

Module

Credit Points Type

Compulsory Modules

WCH 401 Business chemistry I

WCH 402 Business chemistry II

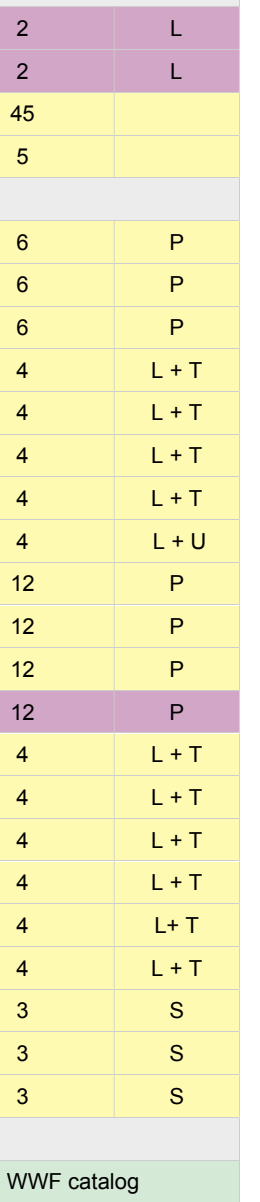

CHE 420 Master's project

CHE 421 Master's exam

Optional Modules: 19 credit points

CHE 321 IC lab course II

CHE 322 OC lab course II

CHE 323 PC lab course II

CHE 430 Inorganic chemistry VII

CHE 431 Organic chemistry VII

CHE 432 Physical chemistry VII

CHE 433 Biophysical chemistry

CHE 434 Chemical biology

CHE 435 Project lab course AC

CHE 436 Project lab course OC

CHE 437 Project lab course PC

WCH 403 Industry practical course

CHE 324 Inorganic chemistry $V$

CHE 325 Inorganic chemistry VI

CHE 326 Organic chemistry $V$

CHE 327 Organic chemistry VI

CHE 328 Physical chemistry $V$

CHE 329 Physical chemistry VI

CHE 438 Master's seminar IC

CHE 439 Master's seminar OC

CHE 440 Master's seminar PC

17 credit points, with at least 8 credit points from the WWF catalog

Fig. 1. cont.

within six months. Fields include technology and market analysis or intellectual property analysis studies. The companies are cordially invited to offer topics.

\section{Acceptance and Experiences}

When the program was started in fall 2004, a handful of students acted as 'pioneers'. Meanwhile the number has increased to a level of 40 students (in addition to 30-40 chemistry students) (Fig. 2). Interestingly, the number of chemistry students did not decrease at the same time. This indicates that we were able to attract students with interest in chemistry, who would not have selected chemistry but other programs like business administration. This is confirmed by the comments from the WiChem students themselves: "We are very interested in chemistry, but we don't really enjoy doing research".

Many major chemical and pharmaceutical companies have been hiring practical students, students for the Master thesis, and

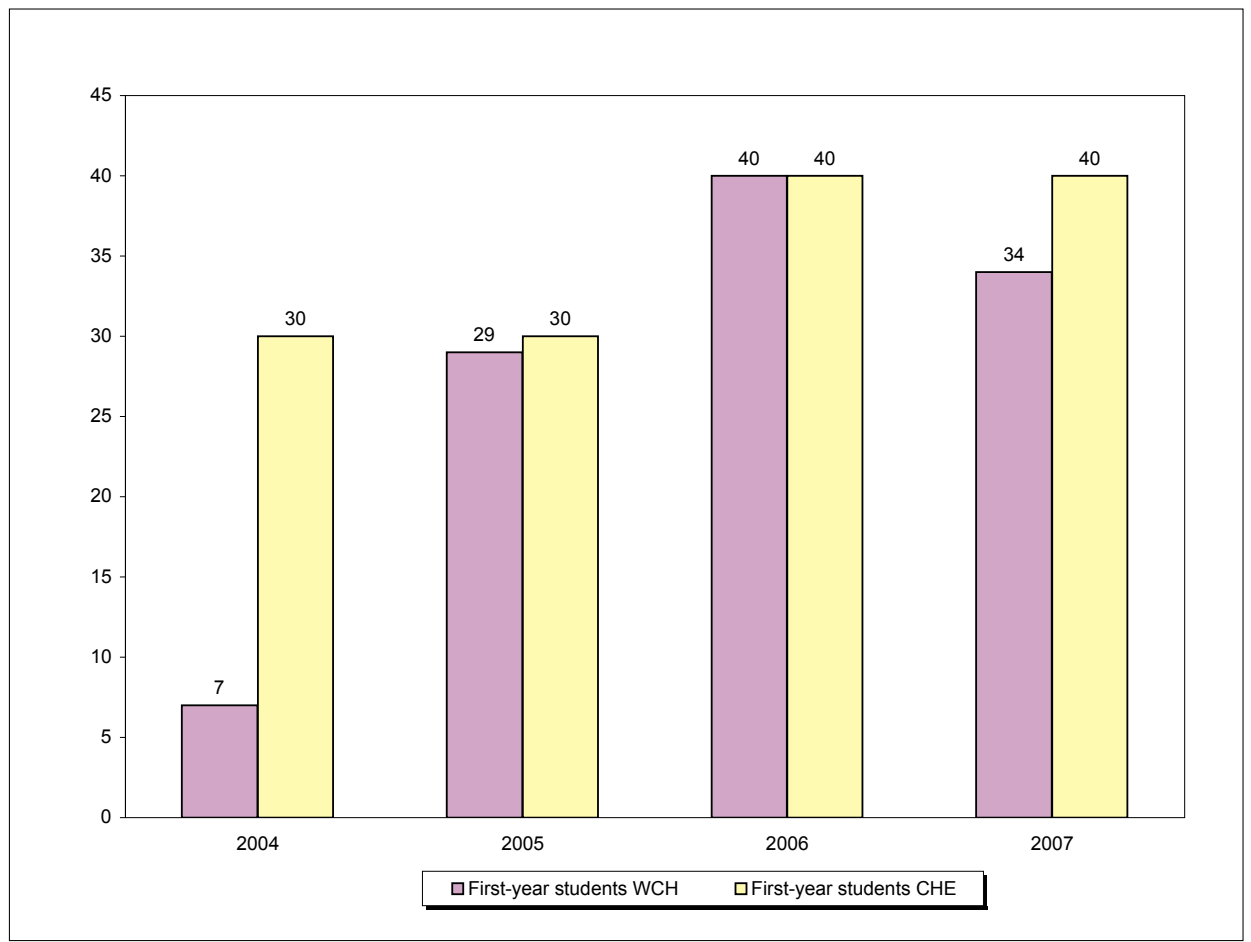

Fig. 2. 
professionals. In Germany, e.g. BASF, Henkel, Boehringer Ingelheim, Merck KgaA, as well as major consulting firms have hired people with a Master's degree. In Switzerland, Lonza, Novartis, Sigma-Aldrich and DSM have hired graduates (imported from German universities, because there are no Swiss graduates yet) or students for practical courses and the Master's thesis. Also small and middle-sized high-tech companies have started to profit from these tailormade educated young people.

The Chemistry and Business Administration Program offers chemical companies of any size many advantages:

- graduates who are attuned to economical frames;

- graduates who are able to communicate with scientists and business people in the company;

- graduates who are educated to start at interface positions immediately;

- practical students for small projects;

- Master's students for Master's thesis projects

- PhD students for chemical business issues

Meeting students early during the practical course or Master's thesis helps the companies to learn their strengths and weaknesses and to select early the top graduates they are looking for.

Another segment which can profit from these graduates is small and middle-sized companies. Here several functions are very often combined in a single person. Management skills and entrepreneurial mentality are much more important in such cases. Managers often have to guide application specialists, are heavily involved in sales negotiations with customers and have to organize marketing campaigns by themselves. They are involved in selecting distribution partners all over the world, reporting to the Board and many other management responsibilities. For such jobs Chemistry and Business Graduates are ideally educated.

The management and business knowhow furthermore is essential for successful entrepreneurship which is strongly supported by the governments of most countries. Often excellent ideas are not commercialized because of a lack in commercial thinking of university scientists. Or brilliant scientific ideas fail in the market due to a deficit in management and business know-how. Chemistry and Business graduates or a mix of them with chemists or other scientists may help to increase the number of successful start ups in the future. Equity capital acquisition is accelerated by presenting entrepreneurs with a business background and furthermore, business know-how helps to prevent fundamental faults after the start.

\section{Outlook}

The experiences of the first classes have shown that the program is a success.
Student numbers are as high as in the chemistry program without losing chemistry students. In total more young people could be attracted to chemistry; students who are interested in chemistry but not interested in a scientific career. It is likely that some of the students have the potential to outperform and they will look forward to a great career in the top management in chemical companies.

In the near future we will make efforts to attract more lecturers from outside of the university, teaching challenging issues selected out of the real life in chemical industry; and of course, by 'practioners'. Current activities adjust the program to an even more international format, i.e. we initiate coordinated programs with foreign universities. This will further simplify studies at foreign universities for undergraduates and ensure that time is not wasted with such an exchange.

Industry has the opportunity to get involved in the program by expressing their wishes and ideas and by active support. In particular human resources management has the opportunity to contact excellent students early. Responsible people at the university have learned that the students are highly motivated. Now the industry has the chance to profit from them.

Received: February 6, 2008 